\title{
Identification and Characterization of BRCA1 and BRCA2 Founder Mutations
}

\author{
T. Sidoni ${ }^{1}$, V. Cocciolone ${ }^{1}$, G. Giannini ${ }^{2}$, A. Russo ${ }^{3}$, F. Baudi ${ }^{4}$, K. Cannita ${ }^{1}$, C. Ficorella ${ }^{1}$, \\ S. Iacobelli ${ }^{5}$ and E. Ricevuto ${ }^{1, *}$
}

${ }^{1}$ Medical Oncology, Department of Experimental Medicine, University of L'Aquila, L'Aquila, Italy; ${ }^{2}$ Service of Molecular and Ultrastructural Pathology, Dept. Experimental Medicine and Pathology, University "La Sapienza", Rome, Italy; ${ }^{3}$ Department of Surgery and Oncology, Regional Reference Center for the Biomolecular Characterization and Genetic Screening of Hereditary Tumors, University of Palermo, Palermo, Italy; ${ }^{4}$ Dipartimento di Medicina Sperimentale e Clinica "G. Salvatore", Università degli Studi di Catanzaro "Magna Graecia", Italy; ${ }^{5}$ Department of Oncology and Neurosciences, Section of Medical Oncology, University of Chieti, Chieti, Italy

\begin{abstract}
A large number of cancer predisposing BRCA1/BRCA2 mutations have been reported, with a wide variety among populations. In some restricted groups, specific germline mutations in these tumor suppressor genes have been found with high predominance, due to a founder effect.

We focused our review on the Italian founder mutations.

The first Italian BRCA1 founder mutation, 5083del19, was found in Calabria: the presence of common allele in all carriers of this mutation (also in families with Calabrian origin living in other parts of Italy) confirmed its founder effect. The same BRCA1 mutation was identified in the Sicilian population, but only the haplotype analysis can reveal the common ancestor of these groups. Another BRCA1 founder mutation, 4843delC, was found in Sicily. Four distinct BRCA1 mutations are attributable to families original from Tuscany: 3348delAG, 3285delA, 1499insA and 5183delTGT; the latter has been shown to be a founder mutation from North-Eastern Italy. The first BRCA2 mutation was identified in Sardinia, 8765delAG, a mutation already described as a founder mutation in Jewish-Yemenite families and also in French-Canadian population but with independent origins of carriers in these three populations. BRCA2 3951 del 3 and BRCA1 917delTT have been described as founder mutations in Middle Sardinia and in South and Middle Sardinia, respectively.

Studies regarding prevalence and penetrance of founder mutations can allow to quantify the degree of homogeneity within a population and can surely help the geneticist and oncologist to simplify their choices in the genetic testing on high-risk families, on the basis of their ethnical origin.
\end{abstract}

Keywords: BRCA1, BRCA2, founder mutation.

\section{INTRODUCTION}

About $5-10 \%$ of breast and ovarian cancer cases are hereditary and a proportion of $30-50 \%$ has been attributed to germline mutation of BRCA1 and BRCA2 genes [1-3].

Several studies have assessed the BRCA1 and BRCA2 deleterious mutations prevalence in different cohorts, in particular investigating the geographical distribution as a consequence of a founder effect $[4,5]$. Then, the BRCA $1 / 2$ mutations distribution and prevalence in carriers with breast and ovarian cancer familiarity depend on population studies for ethnic and geographical diversity.

The first example of a founder effect was found in Ashkenazi Jews population. This has ancestor from Eastern and Central Europe and several founder and recurrent mutations have been identified in this ethnically restricted

*Address correspondence to this author at the Medical Oncology, Departnent of Experjmental Medicine, University of L'Aquila, Italy; Tel: 0862/168585; Fax: 0862/368585;

E-mails: enrico.riceruto@rmivaq.it, ricevuto2@interÎree.it population. In particular three founder mutations have been identified, two BRCA1 and one BRCA2 mutation, present in up to $2.5 \%$ of Ashkenazi Jews women, compared with $0.2 \%$ of BRCA $1 / 2$ mutation carriers in the general population [6, 7]. The BRCA1 185 delAG mutation was found in $1 \%$ of the members of this population and in $20 \%$ of women with early-onset breast cancer (before 42y) [8]; BRCA1 5382insC was found in $0.13 \%$ of this ethnic group [6, 8-15] and BRCA2 6174delT founder mutation is present in $1.52 \%$ of Ashkenazi [6].

The other most important founder mutations of BRCA1 and BRCA2 genes have been described in Icelaners $[6,7$, 16], French-Canadians [17-22], Jewish-Yemenites [19, 20, 23], Norwegians [24-27], Swedes [28-31], Finss [32, 33], Dutch [34-36], Spanish [37], Hispanic population [38, 39)], Afro-Americans [40, 41], Japanese [42-44], Chinese [45, 46]. The most important BRCA1/2 founder mutations are presented in Table $\mathbf{1}$.

This characterization of founder mutations is important for more accurate risk assessment and more specific genetic 
Table 1. Most Important Founder Mutations Identified in BRCA1 and BRCA2

\begin{tabular}{|c|c|c|}
\hline Population & Mutation & Reference \\
\hline Icelanders & BRCA2-6174delT,995delG & {$[6,7,16]$} \\
\hline French-Canadians & $\begin{array}{l}\text { BRCA1-C4446T } \\
\text { BRCA2-8765delAG,3398de15 }\end{array}$ & {$[17-22]$} \\
\hline Norwegians & BRCA1-1135insA,1675delA,816delGT,3348delAG & {$[24,27]$} \\
\hline Swedes & BRCA1-3171 ins5 & {$[28-31]$} \\
\hline Finns & $\begin{array}{l}\text { BRCA1-IVS11+3A }<\mathrm{G} \\
\text { BRCA2-9345+1G }>\text { A,C7708T,T8555G }\end{array}$ & {$[32,33]$} \\
\hline Spanish & $\begin{array}{l}\text { BRCA1-5272-1G }>\text { A } \\
\text { BRCA2-5374del4,5344del4,9538delAA }\end{array}$ & {$[37]$} \\
\hline Hispanics & $\begin{array}{l}\text { BRCA1-S995X,2552delC,3450del4,A1708E } \\
\text { BRCA2-3034del4 }\end{array}$ & {$[38,39]$} \\
\hline Afro Americans & $\begin{array}{l}\text { BRCA1-943ins10,1832del5,5296del } \\
\text { BRCA2-IVS13+1G>A }\end{array}$ & {$[40,41]$} \\
\hline Japanese & $\begin{array}{l}\text { BRCA1Q934X,L63X } \\
\text { BRCA2-5802del4 }\end{array}$ & {$[42-44]$} \\
\hline Chinese & $\begin{array}{l}\text { BRCA1-1081delG } \\
\text { BRCA2-3109c }>t\end{array}$ & {$[45,46]$} \\
\hline
\end{tabular}

The table describes the most important founder mutations reported in the text.

counseling [4]. Founder mutations allowed for focused studies about penetrance, expression and genetic modifiers of risk [5].

In Italy in the last ten years, a few number of founder recurrent mutations have been observed [47], in fact $4-27 \%$ of BRCA1/2 mutations recurred in unrelated families but the founder effect has been demonstrated only in a small number of mutations [48-51].

The aim of this review is to examine the founder mutations in Italian population and to compare them with the same mutations detected in other populations (Tables $\mathbf{2}, \mathbf{3}$ ).

\section{Founder Mutations in Calabria}

In 2001, the first case of BRCA1 founder mutation in Italian population was described. BRCA1 5083del19 mutation shows have a founder effect in a geographically and historically homogeneus population from Calabria, Italian region, and it specifically characterizes such population and can be discovered in most of the patients affected by breast and ovarian cancer [52]. Twenty-four unrelated families at risk for breast and/or ovarian cancer predisposing syndrome were selected for BRCA1 genetic testing. six BRCA1 mutation carriers and three different mutations were identified. The BRCA1 5083del19 mutation was found in four unrelated families $(33 \%$ of the overall mutations). All four families were from the same geographic area. The allelotype analysis by using five microsatellite markers, highlighted the common allele in all mutation carriers, affected and unaffected, suggesting the founder effect in this population, also in concordance with a

Table 2. BRCA1 BRCA2 Founder Mutations in Italy

\begin{tabular}{|l|l|l|l|}
\hline Gene & Mutation Type & Country & Reference \\
\hline \hline BRCA1 & 5083 del19 & Calabria & {$[52-54]$} \\
& & Sicily & {$[55,56]$} \\
& 4843 delC & Sicily & {$[55,57]$} \\
& 3348 delAG & Tuscany & {$[51,58]$} \\
& 3285delA & Tuscany & {$[51]$} \\
& 1499insA & Tuscany & {$[50,51,59]$} \\
& 5183delTGT & North-Italy & {$[51,60]$} \\
& 917delTT & Sardinia & {$[55,56,65]$} \\
\hline \multirow{2}{*}{ BRCA2 } & 8765delAG & Sardinia & {$[20,49,65]$} \\
& 3952delTAGinsAT & Sardinia & {$[64,65]$} \\
\hline
\end{tabular}

The table describes the BRCA1/BRCA2 Italian founder mutations reported in the text. 
Table 3. Common BRCA1/BRCA2 Founder Mutation

\begin{tabular}{|l|l|l|l|}
\hline Gene & Mutation Type & Country & Reference \\
\hline \hline BRCA1 & \multirow{2}{*}{3348 delAG } & Tuscany & {$[51,58]$} \\
& \multirow{2}{*}{1135 insA } & Norway & {$[25,26]$} \\
& & Italy & {$[27]$} \\
& & Norway & {$[27]$} \\
& & Germany & {$[27]$} \\
\hline \multirow{2}{*}{ BRCA2 } & \multirow{2}{*}{8765 delAG } & French- Canadian & {$[27]$} \\
& & Sardinia & {$[20,49,65]$} \\
& & Jewish-Yemenite & {$[19,20,23]$} \\
& & French- Canadian & {$[17-20]$} \\
\hline
\end{tabular}

The table compare the Italian founder mutations with the same detected in other populations and reported in the text.

homogeneous background of the Calabrian populations. The research group of l'Aquila University identified the same mutation in two families of Calabrian origin. Allelotype analysis confirmed the presence of common allele [52].

In 2002, a Canadian study described BRCA1 5083del19 mutations in five out of 116 families with breast or/and ovarian cancer proband and at least one Italian ancestor. Only 3 of these have Calabrian origin [53].

In 2004, the "Italian Consortium of Hereditary Breast and Ovarian Cancer" confirmed that a few rate of $23 \%$ of BRCA $1 / 2$ mutation prevalence in Italian population proved to be recurrent in a particular geographic area. The BRCA1 5083del19 mutation can be surely considered as the Calabrian founder mutation [54].

A Sicily study of 2006 had shown the presence of BRCA1 5083del19 mutation in Sicilian population. This mutation was found in four of 106 families selected for BRCA1/2 genetic test and all families confirmed their Sicilian origin [55]. The allelotype analysis proved the presence of common allele in all carriers of this mutation, suggesting the founder effect in Sicilian population [56]. Only the haplotype analysis in all BRCA1 carriers in Italy using the same microsatellite markers, can explain if Calabrian and Sicily's families have a common ancestor [56].

\section{Founder Mutations in Sicily}

One hundred and six families from Sicily with familiar history of breast and ovarian cancer were selected to be submitted to BRCA1/2 mutations analysis. A new BRCA1 4843 delC mutation in the family history of breast and ovarian cancer in two families demonstrated high penetrance of this mutation.

Either mutation's carriers had shown to have the same sequence variants. Allelotype analysis by five polymorphic microsatellite markers has noticed the presence of a common allele associated with this mutation in all the carrier subjects (affected and unaffected). This shows the founder effect of this BRCA1 4843delC mutation in the Sicilian population [57].

\section{Founder Mutations in Tuscany}

The Tuscany's study has verified the founder mutations presence in a set of families original from the CentralEastern part of Tuscany.

One hundred and four probands with family history of breast and ovarian cancer were submitted to BRCA1/2 genetic test. Thirty-five (34\%) BRCA1/2 carrier families were detected: 22 BRCA1 with ten different mutations and 13 BRCA2 with twelve different germline mutations [51].

Four distinct BRCA1 mutations was attributable to families original from this geographic area [51].

The BRCA1 3348delAG mutation were observed in twelve families, 3 male breast cancer cases original from Tuscany previously verified in a population study [58]; the BRCA1 3285delA mutation has been observed in three families $(13 / 22 ; 57 \%)$. The haplotype analysis of nine microsatellite markers, proves that both have common haplotypes, derived from common ancestor, therefore demonstrating the founder effect of these mutations. The 3348 delAG mutation is estimated to have been originated 129 generations ago, corresponding to 3,225 years [51].

Also, two BRCA1 mutations 1499insA and 5183delTGT were detected in two unrelated families. In a previous study, the haplotype analysis in 1499ins A mutations carriers revealed a founder allele originating from Western Tuscany, estimated to be present about 30 generations ago, or 750 years $[50,59]$. The BRCA1 5183delTGT mutation has been shown to be a founder mutation from North-Eastern Italy $[51,60]$.

The BRCA2 mutations have the largest variability; $9345 \mathrm{G}>\mathrm{A}$ mutation has been identified in two unrelated families from Central-Eastern Tuscany already described in another patient from Tuscany [61]. The founder effect of this mutation hasn't been demonstrated yet.

\section{Founder Mutations in Sardinia}

Sardinia's population shows a low level of genetic heterogeneity due to geographical isolation and strong genetic drift; then the founder effect of mutation is expected to be found $[62,63]$.

In 2000, the first BRCA2 founder mutation in Italian breast cancer families was described. Seven breast cancer families with multiple affected members in the absence of ovarian cancer cases were selected and they all originated from different small villages located in the northern-central part of Sardinia. The BRCA2 genotyping analysis with markers flanking BRCA2 locus identified a common haplotype in four of seven families, suggesting the presence of a BRCA2 founder mutation. Direct sequencing allowed the identification of $8765 \mathrm{delAG}$ mutation that was found, besides in breast cancer probands, also in one prostate and in one bladder cancer patient with shared haplotype [49].

The BRCA2 8765delAG mutation was already described as a founder mutation in Jewish-Yemenite families [23] and also in French-Canadian population [17, 18]. A previous study through the French-Canadian and Jewish-Yemenite haplotypes mutation carriers comparison, showed the 
independent origins of carriers in these two populations [19].

In 2007, a study was conducted to evaluate the prevalence of BRCA2 8765delAG mutation in Sardinia population and to show the possible common ancestral origin of all mutation carriers from Sardinian and Jewish-Yemenite population, also referring to data among French-Canadian families. In North Sardinian families the identification of identical haplotype in all family members of BRCA2 mutation carriers, indicated that this mutation is a founder in this geographic area. Moreover, the haplotype analysis comparison in the three analyzed populations indicated that BRCA2 mutation has an independent origin in these geographically different populations [20].

Another study of 2007 described the BRCA2 3952del TAGinsAT mutations in six patients from a small village of the central part of Sardinia and with a family history of breast cancer. The haplotype analyses suggests that all mutation carriers had a common ancestor, proving the founder effect in Middle Sardinia population [64].

A study published in 2009 [65] reports the prevalence of BRCA1/2 mutations in patients with positive family history of breast and/or ovarian cancer from Sardinia. The BRCA2 8765delAG mutation and 3952delTAGinsAT mutation were previously described as founder mutations in North and Middle Sardinia, respectively. In three unrelated families from South and Middle Sardinia, was identified a BRCA1 917delTT mutation already reported in breast/ovarian cancer families from Sicily $[55,56]$. In this study BRCA2 mutations were more frequent than BRCA1 mutations, due to the high proportion of $\mathrm{BRCA} 2$ founder mutation carriers.

\section{Northern Italian Founder Mutations}

The BRCA1 Val1688del (5183delTGT) deleterious mutation was found in a study of 1998 [66]; this mutation was already described in Tuscany families with North-Italian ancestral origins [51]. The new study in 2008, by molecular screening of 600 high risk breast and breast/ovarian cancer families, identified this variant in eight mutation carriers. Three additional unrelated families from Northeast Italian region, carriers of this variant, were added to the study [60]. The microsatellite markers analysis confirmed the presence of a common haplotype in all the 11 families, therefore demonstrating the common ancestor and founder effect in this region. Moreover, this study shows that BRCA1 Val1688del mutation has a pathogenic effect [60].

\section{Italian Founder Mutations Compared with the Same Mutations Detected in Other Populations}

In a Norway study four BRCA1 mutations were reported that account for $68 \%$ of the BRCA1 mutation carriers: 1675delA, 816delGT, 1135insA and 3348delAG, the latter is the same mutation found in Tuscany $[51,58]$; the Norwegian families mutation carriers with breast and ovarian cancer history were from South-West coast of Norway $[25,26]$.

In a 2006 study was performed haplotype analysis on breast and ovarian cancer families carriers of BRCA1 1135ins A mutation, originating from four different geographic regions: French Canadian, Italian and Dutch population, compared with the previously reported Norway founder haplotype. Three distinct haplotypes were found, which would indicate an independent origin of this mutation in these populations. On the contrary, the haplotype analysis showed the founder effect of this mutation in Norwegian population [27].

The founder mutations in BRCA1/BRCA2 genes were identified in Canadian breast and breast/ovarian cancer families of French ancestry. In particular, in 113 ovarian cancer probands unselected for family history, eight germline mutations were found: 5 families BRCA1 C4446T mutation carriers and two families BRCA2 8765delAG mutation carriers. The latter is the most common mutation described in French-Canadian breast and ovarian cancer families [21, 22] and was found in Italy, Sardinia population $[17,18]$. This 8765 delAG mutation was already described as a founder mutation in Jewish-Yemenite families [23]; the comparison of the three populations indicated that BRCA2 mutation has an independent origin in these geographically different populations [20].

\section{CONCLUSION}

In summary, in Italy BRCA1 founder mutations are prevalent respect to BRCA2 founder mutations; in fact seven BRCA1 and two BRCA2 mutations have been detected. Two BRCA2 mutations were found in Sardinia region where BRCA2 mutations are prevalent.

The same BRCA1 mutations found in Calabria, which demonstrated to have a founder effect in this geographic region, were identified in the Sicilian population, but only the haplotype analysis can reveal the common ancestor of these groups.

Two Italian founder mutations, one BRCA1 found in Tuscany region and one BRCA2 detected in Sardinia region, were also reported in Norway and Jewish-Yemenite, FrenchCanadian populations respectively; for BRCA2 mutations were reported the independent origins of carriers in these three populations.

The prevalence and penetrance of founder mutations in a population allow to focus the genetic testing on high-risk families, on the basis of their ethnical origin, through a more accurate estimate of the prior probability of carrying a BRCA1/2 mutation.

\section{CONFLICT OF INTEREST}

None declared.

\section{ACKNOWLEDGEMENT}

None declared.

\section{REFERENCES}

[1] Miki Y, Swensen J, Shattuck-Eidens D, et al. A strong candidate for the breast and ovarian cancer susceptibility gene BRCA1. Science 1994; 266: 66-71.

[2] Wooster R, Stratton MR. Breast cancer susceptibility: a complex disease unravels. Trends Genet 1995; 11: 3-5.

[3] Ford D, Easton DF, Stratton M, et al. Genetic heterogeneity and penetrance analysis of the BRCA1 and BRCA2 genes in breast cancer families. The Breast Cancer Linkage Consortium. Am J Hum Genet 1998; 62: 676-89. 
[4] Neuhausen SL Ethnic differences in cancer risk resulting from genetic variation. Cancer. 1999; 86(11 Suppl): 2575-82.

[5] Susan L Neuhausen. Founder populations and their uses for breast cancer genetics. Breast Cancer Res 2000; 2: 77-81

[6] Roa BB, Boyd AA, Volcik K, et al. Ashkenazi Jewish population frequencies for common mutations in BRCA1 and BRCA2. Nat Genet 1996; 14: 185-7.

[7] Neuhausen S, Gilewski T, Norton L et al. Recurrent BRCA2 6174delT mutations in Ashkenazi Jewish women affected by breast cancer. Nat Genet 1996; 13: 126-8.

[8] Struewing JP, Abeliovich D, Peretz T, et al. The carrier frequency of the BRCA1 $185 \mathrm{delAG}$ mutation is approximately 1 percent in Ashkenazi Jewis individuals. Nat Genet 1995; 11: 198-200.

[9] Brose MS, Rebbeck TR, Calzone KA, Stopfer JE, Nathanson KL, Weber BL. Cancer risk estimates for BRCA1 mutation carriers identified in a risk evaluation program. J Nat Cancer Inst 2002; 9418: 1365-72.

[10] Robles-Diaz L, Goldfrank DJ, Kauff ND, et al. Hereditary ovarian cancer in Ashkenazi Jews. Fam Cancer 2004; 3: 259-64.

[11] Antoniou A, Pharoah PD, Narod S, et al. Average risks of breast and ovarian cancer associated with BRCA1 or BRCA2 mutations detected in case series unselected for family history: a combined analysis of 22 studies. Am J Hum Genet 2003; 72: 1117-30.

[12] Liede A, Karlan BY, Narod SA. Cancer risks for male carriers of germline mutations in BRCA1 or BRCA2: a review of the literature. J Clin Oncol 2004; 22: 735-42.

[13] Giordano SH. A review of the diagnosis and management of male breast cancer. Oncologist 2005; 10: 471-9.

[14] Friedman LS, Szabo CI, Ostermeyer EA, et al. Novel inherited mutations and variable expressivity of BRCA1 alleles, including the founder mutation 185delAG in Ashkenazi Jewish families. Am J Hum Genet 1995; 57: 1284-97.

[15] Rubinstein WS. Hereditary breast cancer in Jews. Fam Cancer 2004; 3: 249-57.

[16] Thorlacius S, Olafsdottir G, Tryggvadottir L, et al. A single BRCA2 mutation in male and female breast cancer families from Iceland with varied cancer phenotypes. Nat Genet 1996; 13: 117-9

[17] Phelan CM, Lancaster JM, Tonin P, et al. Mutation analysis of the BRCA2 gene in 49 site-specific breast cancer families. Nat Genet 1996; 13: 120- 2

[18] Tonin PN, Mes-Masson AM, Futreal PA, et al. Founder BRCA1 and BRCA2 mutations in French Canadian breast and ovarian cancer families. Am J Hum Genet 1998; 63: 1341-51

[19] Manning AP, Abelovich D, Ghadirian P, et al. Haplotype analysis of BRCA2 8765delAG mutation carriers in French Canadian and Yemenite Jewish hereditary breast cancer families. Hum Hered 2001; 52(2): 116-20

[20] Grazia P, Antonio C, Eitan F, et al. Origin and distribution of the BRCA2-8765delAG mutation in breast cancer. BMC Cancer 2007, 7:132 doi:10.1186/1471-2407-7-132

[21] Tonin PN, Mes-Masson A-M, Narod SA, et al. Founder BRCA 1 and BRCA 2 mutations in French Canadian ovarian cancer cases unselected fo family history. Clin Genet 1999; 55: 318-24.

[22] Tonin PN, Perret C, Lambert JA, et al. Founder BRCA1 and BRCA2 mutations in early-onset French Canadian breast cancer cases unselected for family history. Int J Cancer 2001; 95: 189-93.

[23] Lerer I, Wang T, Peretz T, et al. The 8765delAG mutation in BRCA2 is common among Jews of Yemenite extraction. Am J Hum Genet 1998; 63: 274-9

[24] Andersen TI, Borresen AL, Moller P. A common BRCA1 mutation in Norwegian breast and ovarian cancer families? Am J Hum Genet 1996; 59: 486-7.

[25] Moller P, Heimdal K, Apold J, et al. Genetic epidemiology of BRCA1 mutations in Norway. Eur J Cancer 2001; 37: 2428-34.

[26] Heimdal K, Maehle L, Apold J, et al. The Norwegian founder mutations in BRCA1: high penetrance confirmed in an incident cancer series and differences observedin the risk of ovarian cancer. Eur J Cancer 2003; 39: 2205-13.

[27] Rudkin TM, Hamel N, Galvez M, et al. The frequent BRCA1 mutation 1135insA has multiple origins: a haplotype study in different populations. BMC Med Genet 2006; 7: 15.

[28] Johannsson O, Ostermeyer EA, Hakansson S, et al. Founding BRCA1 mutations in hereditary breast and ovarian cancer in Southern Sweden. Am J Hum Genet 1996; 58: 441-50.
[29] Bergman A, Einbeigi Z, Olofsson U, et al. The western Swedish BRCA1 founder mutation 3171 ins 5 ; a $3.7 \mathrm{cM}$ conserved haplotype of today is a reminiscence of a 1500-year-old mutation. Eur J Hum Genet 2001; 9: 787-93.

[30] Bergman A, Flodin A, Engwall Y, et al. A high frequency of germline BRCA1/2 mutations in western Sweden detected with complementary screening techniques. Fam Cancer 2005; 4: 89-96.

[31] Einbeigi Z, Bergman A, Kindblom LG, et al. A founder mutation of the BRCA1 gene in western Sweden associated with a high incidence of breast and ovariancancer. Eur J Cancer 2001; 37: 1904-9.

[32] Huusko P, Paakkonen K, Launnonen V, et al. Evidence of founder mutations in Finnish BRCA1 and BRCA2 families. Am J Hum Genet 1998; 62(6):1544-8

[33] Sarantaus L, Huusko P, Eerola H, et al. Multiple founder effects and geographical clustering of BRCA1 and BRCA2 families in Finland. Eur J Hum Genet 2000; 8: 757-63.

[34] Peelen T, van Vliet M, Petrij-Bosch A, et al. A high proportion of novel mutations in BRCA1 with strong founder effects among Dutch and Belgian hereditary breast and ovarian cancer families. Am J Hum Genet 1997; 60: 1041-9.

[35] Petrij-Bosch A, Peelen T, van Vliet $\mathrm{M}$, et al. BRCAl genomic deletions are major founder mutations in Dutch breast cancer patients. Nat Genet 1997; 17: 341-5.

[36] Hartmann C, John AL, Klaes R, et al. Large BRCA1 gene deletions are found in $3 \%$ of German high-risk breast cancer families. Hum Mutat 2004; 24: 534.

[37] Infante M, Durán M, Lasa A, et al. Two founder BRCA2 mutations predispose to breast cancer in young women. Breast Cancer Res Treat 2010; 122(2): 567-71.

[38] Weitzel JN, Lagos V, Blazer KR, et al. Prevalence of BRCA mutations and founder effect in high-risk Hispanic families. Cancer Epidemiol Biomarkers Prev 2005; 14: 1666-71.

[39] Torres D, Usman Rashid M, Gil F, et al. High proportion of BRCA1/2 founder mutations in Hispanic breast/ovarian cancer families from Colombia. Breast Cancer Res Treat 2007; 103(2): 225-32.

[40] Gao Q, Neuhausen S, Cummings S, Luce M, Olopade O. Recurrent germline BRCA1 mutations in extended African American families with early-onset breast cancer. Am J Hum Genet 1997; 60: 1233-6.

[41] Olopade OI, Fackenthal JD, Dunston G, et al. Breast cancer genetics in African Americans. Cancer 2003; 97 Suppl): 236-45.

[42] Inoue R, Fukutomi T, Ushijima T, Matsumoto Y, Sugimura T, Nagao M. Germline mutation of BRCA1 in Japanese breast cancer families. Cancer Res 1995; 55: 3521-4.

[43] Ikeda N, Miyoshi Y, Yoneda K, et al. Frequency of BRCA1 and BRCA2 germline mutations in Japanese breast cancer families. Int J Cancer 2001; 91: 83-8.

[44] Sekine M, Nagata H, Tsuji S, et al. Mutational analysis of BRCA1 and BRCA2 and clinicopathologic analysis of ovarian cancer in 82 ovarian cancer families: two common founder mutations of BRCA1 in Japanese population. Clin Cancer Res 2001; 7: 3144-50.

[45] Khoo US, Chan KY, Cheung AN, et al. Recurrent BRCA1 and BRCA2 germline mutations in ovarian cancer: a founder mutation of BRCA1 identified in the Chinese population. Hum Mutat 2002; 19(3): 307-8.

[46] Kwong A, Wong LP, Wong HN, et al. A BRCA2 founder mutation and seven novel deleterious BRCA mutations in southern Chinese women with breast and ovarian cancer. Breast Cancer Res Treat 2009; 117(3): 683-6.

[47] Ferla R, Calo V, Cascio S, et al. Founder mutations in BRCA1 and BRCA2 genes. Ann Oncol 2007; 18(Supp 6): vi93-vi8

[48] Nedelcu R, Liede A, Aubè J, et al. BRCA mutation in in Italian breast/ovarian cancer families. Eur J Hum Genet 2002, 10: 105-52

[49] Pisano M, Cossu A, Persico I, et al. Identification of a founder BRCA2 mutation in Sardinia. Brit J Cancer 2000, 82: 553-9.

[50] Marroni F, Cipollini G, D'Andrea E, et al. Reconstructing the Genealogy of a BRCA1 Founder Mutation by Philogenetic Analysis. Ann Hum Genet 2008, 72: 310-8

[51] Papi L, Putignano AL, Congregati C, et al. Founder mutations account for the majority of BRCA1-attributable hereditary breast/ovarian cancer cases in a population from Tuscany, Central Italy. Breast Cancer Res Treat 2009; 117(3): 497-504. 
[52] Baudi F, Quaresima B, Grandinetti C, et al. Evidence of a founder mutation of BRCA1 in a highly homogeneous population from southern Italy with breast/ovarian cancer. Hum Mutat 2001; 18: 163-4.

[53] Nedelcu R, Liede A, Aube J, et al. BRCA mutations in Italian breast/ovarian cancer families. Eur J Hum Genet 2002; 10: 150-2.

[54] Cipollini G, Tommasi S, Paradiso A, et al. Genetic alterations in hereditary breast cancer. Ann Oncol 2004; 15 (Suppl 1): I7-I13.

[55] Russo A, Calo V, Agnese V, et al. BRCA1 genetic testing in 106 breast and ovarian cancer families from southern Italy (Sicily): a mutation analyses. Breast Cancer Res Treat 2007; 105(3): 267-76.

[56] Russo A, Calò V, Augello C, Bruno L, et al. Is BRCA1-5083del19, identified in breast cancer patients of Sicilian origin, a Calabrian founder mutation? Breast Cancer Res Treat 2009; 113: 67-70

[57] Russo A, Calò V, Augello C, Bruno L, et al. 4843delC of the BRCA1 gene is a possible founder mutation in Southern Italy (Sicily). Ann Oncol 2007; 18(Suppl 6): vi99-102.

[58] Ottini L, Rizzolo P, Zanna I, et al. BRCA1/BRCA2 mutation status and clinical-pathologic features of 108 male breast cancer cases from Tuscany: a population-based study in central Italy. Breast Cancer Res Treat 2009; 116(3): 577-86.

[59] Caligo MA, Ghimenti C, Cipollini G, et al. BRCA1 germline mutational spectrum in Italian families from Tuscany: a high frequency from novel mutations. Oncogene 1996; 13: 1483-8.
[60] Malacrida S, Agata S, Callegaro M, et al. BRCA1 p.Val1688del is a deleterious mutation that recurs in breast and ovarian cancer families from Northeast Italy. J Clin Oncol 2008; 26(1): 26-31.

[61] Bonatti F, Pepe C, Tancredi M, et al. RNA-based analysis of BRCA1 and BRCA2 gene alterations. Cancer Genet Cytogenet 2006; 170(2): 93-101.

[62] Caramelli D, Vernesi C, Sanna S, et al. Genetic variation in prehistoric Sardinia. Hum Genet. 2007; 122(3-4): 327-36.

[63] Service S, DeYoung J, Karayiorgou M, et al. Magnitude and distribution of linkage disequilibrium in population isolates and implications for genome- wide association studies. Nat Genet 2006; 38(5): 556-60.

[64] Monne M, Piras G, Fancello P, et al. Identification of a founder BRCA2 mutation in Sardinian breast cancer families. Fam Cancer 2007; 6(1): 73-9

[65] Palomba G, Loi A, Uras A, et al. A role of BRCA1 and BRCA2 germline mutations in breast cancer susceptibility within Sardinian population. BMC Cancer 2009; 9: 245.

[66] Montagna M, Santacatterina M, Corneo B, et al. Identification of seven new BRCA1 germline mutations in Italian breast and breast/ovarian cancer families. Cancer Res 1996; 56(23): $5466-9$. 